\title{
Editorial: Why Look into Media Planning?
}

JOSEPH T. PLUMMER

Co-Editor

joseph.plummer@

mccann.com
There IS ONE ARENA of the advertising industry that has undergone enormous change in the past decade and you guessed it-media! The technology of media has undergone amazing change from the growth of the internet and satellite radio, to the emergence of wireless and video games as an advertising channel, and the continuing segmentation of traditional media like television, magazines, and newspapers. We have seen the emergence of branded content, which in some aspects represents a return to the early days of sponsorship on network shows and in other aspects represents the fusion of two disciplines such as custom publishing. This year advertisers will spend more with Yahoo and Google than with CBS and Fox, which was unthinkable 5 to 10 years ago during the dot-com bust.

Thus, there is no way a single issue (or even multiple issues for that matter) of the Journal of Advertising Research can fully explore this cornucopia of media change. But we can, we hope, stimulate a dialogue on what these changes might mean to marketing and media strategy, and intro- duce some new ideas for research to guide intelligent media planning. I have asked two visionaries, Ira Carlin of Magna Global and Art Tauder of Thunder House and the MIT Media Lab, to offer an overview of the future of media planning (Ira) and the future of advanced/interactive television (Art) to replace the usual lengthy message from the journal editor.

I hope this issue of $J A R$ will stimulate debate and new thinking. As Art Tauder states: "We must put an end to psychosclerosis by (1) opening up collaboration with media professionals in all marketing communication disciplines, (2) cutting through the technology jargon, (3) updating the research on the relationship between programming content and advertising effectiveness, and (4) lead by developing programming concepts that deliver value to targeted audiences."

Finally, a large thank you very much to the growing number of you who are sending the JAR your work. My hope is that more of you will share your thinking, experiences, and research knowledge in the near future. 